\title{
GERMINAÇÃO DE SEMENTES DE EMBIRUÇU (Pseudobombax grandiflorum (Cav.) A. Robyns) EM DIFERENTES ESTÁDIOS DE MATURAÇÃO E SUBSTRATOS
}

\author{
José Carlos Lopes*, Miele Tallon Matheus**, Nathale Bicalho Corrêa***, Danilo Paulúcio da Silva**** \\ *Eng. Agrônomo, Dr., Depto. de Produção Vegetal, UFES - jclopes@cca.ufes.br; jcufes@bol.com.br \\ **Eng. Florestal, Mestrando em Produção Vegetal, UFES - miele.tallon@bol.com.br \\ ***Eng. Agrônoma, Mestranda em Produção Vegetal, UFES - nathalebc@yahoo.com.br \\ ****Eng. Agrônomo, Mestrando em Engenharia Agrícola, UFV - daniloagronomia@yahoo.com.br \\ Recebido para publicação: 01/06/2007 - Aceito para publicação: 25/09/2007
}

\begin{abstract}
Resumo
O objetivo deste trabalho foi avaliar a germinação de sementes de embiruçu (Pseudobombax grandiflorum (Cav.) A. Robyns), colhidas em vários estádios de maturação, utilizando-se diferentes substratos. Os estádios avaliados foram 30,60 e 80 dias após a antese (DAA) e os substratos utilizados foram papel, areia e vermiculita. O delineamento experimental utilizado foi o inteiramente casualizado (DIC), num esquema fatorial $3 \times 3$ (três períodos de maturação x três substratos), com quatro repetições de 25 sementes, sendo a comparação entre as médias dos tratamentos efetuada pelo teste de Tukey $(\alpha=0,05)$. A vermiculita favoreceu maior porcentagem e velocidade de germinação das sementes com 60 DAA, enquanto sementes com 80 DAA germinaram igualmente nos três substratos, embora a areia tenha proporcionado maior velocidade de germinação nesse estádio.

Palavras-chave: Pseudobombax grandiflorum; espécie florestal; teor de água; formação de sementes; vigor.
\end{abstract}

\begin{abstract}
Germination of embiruçu (Pseudobombax grandiflorum (Cav.) A. Robyns) seeds in different phases of maturity and substrates. The objective of this research was to evaluate the germination of embiruçu seeds harvested in different phases of maturity in different substrates. The evaluated phases were 30 , 60 and 80 days after the anthesis (DAA) and the substrates used were paper, sand and vermiculite. The experimental design utilized was the completely randomized (DIC), in a $3 \times 3$ factorial scheme (three periods of maturity $\mathrm{x}$ three substrates), with four replications of 25 seeds. The comparison among the averages of the treatments was made using the Tukey test $(\alpha=0,05)$. Vermiculite favored higher percentage and velocity of germination of seeds with 60 DAA, while seeds with 80 DAA similarly germinated in the three substrates, although sand had proportionate higher velocity of germination in this phase.

Keywords: Pseudobombax grandiflorum; forest species; water content; seed formation; vigor.
\end{abstract}

\section{INTRODUÇÃO}

Pseudobombax grandiflorum (Cav.) A. Robyns (embiruçu) é uma espécie arbórea pertencente à família Bombacaceae, de madeira muito leve e macia ao corte, podendo ser empregada em caixotaria e miolo de compensados, além de ser extremamente ornamental e ótima para plantios em áreas degradadas (LORENZI, 2002). Espécie nativa do Brasil, o embiruçu ocorre nas regiões Nordeste (Alagoas, Bahia), Centro-Oeste (Mato Grosso), Sudeste (Minas Gerais, São Paulo, Rio de Janeiro) e Sul (Paraná e Santa Catarina) (DUARTE, 2006).

Apesar do aumento considerável de conhecimentos relativos à análise de sementes de espécies florestais, a maioria delas carece ainda de subsídios básicos referentes às exigências quanto às condições ótimas de germinação (ANDRADE et al., 2000; VARELA et al., 2005). Vários fatores influenciam os resultados do teste de germinação, entre eles a qualidade do substrato. Inúmeros materiais podem ser empregados como substrato, devendo-se levar em conta a sua disponibilidade, custo e características 
físico-químicas (NICOLOSO et al., 2000). O substrato, além de servir como suporte para as plântulas após a emergência, deve proporcionar adequado suprimento de ar, água, nutrientes e, sobretudo, ser isento de agentes fitopatogênicos. Para a escolha do substrato a ser utilizado nos testes de germinação, o tamanho e a forma das sementes são dois fatores importantes (FIGLIOLIA et al., 1993), uma vez que, em função do tamanho e exigências ecofisiológicas das sementes quanto à umidade e luz, cada substrato é utilizado de maneira que ofereça maior praticidade nas contagens e avaliação das plântulas, mantendo a capacidade de suprir as condições ideais no decorrer do teste de germinação (POPINIGIS, 1985).

A carência de conhecimentos básicos sobre sementes de espécies florestais também é observada em relação a sua qualidade. Um dos fatores que influenciam a qualidade das sementes é a maturação, sendo que a época de colheita, tanto na própria árvore quanto no solo, nem sempre coincide com o seu pleno vigor, e a colheita feita antes ou após o amadurecimento poderá influir desfavoravelmente sobre a muda (BORGES; BORGES, 1979). As modificações morfológicas, bioquímicas e fisiológicas nos frutos e sementes durante a maturação são utilizadas para a determinação do ponto de maturidade (PIÑARODRIGUES; AGUIAR, 1993). Na literatura, os trabalhos sobre maturação de espécies florestais são em número menor se comparados aos das espécies de grandes culturas (FONSECA et al., 2005), principalmente pelas dificuldades impostas pelas adversidades nos locais de ocorrência da espécie (LOPES; SOARES, 2006), destacando-se Copaifera langsdorffii Desf. (BORGES; BORGES, 1979); Trema micrantha (L.) Blume. (CASTELLANI; AGUIAR, 1998); Tibouchina granulosa Cogn. (LOPES et al., 2005); Tabebuia chrysotricha (Mart. ex DC.) Standl (FONSECA et al., 2005) e Miconia cinnamomifolia (DC.) Naud. (LOPES; SOARES, 2006).

Dada a existência de poucas informações sobre o comportamento germinativo das sementes de Pseudobombax grandiflorum, o presente trabalho objetivou avaliar a germinação das sementes dessa espécie quando colhidas em estádios de maturação diferentes e mantidas em diferentes substratos.

\section{MATERIAL E MÉTODOS}

Foram etiquetadas flores de árvores de embiruçu existentes no campus do Centro de Ciências Agrárias da Universidade Federal do Espírito Santo (CCA-UFES), em Alegre (ES), nas coordenadas geográficas $20^{\circ} 45^{\prime} \mathrm{S}$ e $41^{\circ} 28^{\prime} \mathrm{W}$ e altitude de $150 \mathrm{~m}$, entre os dias $05 / 06 / 2006$ e $02 / 07 / 2006$. Os frutos foram coletados 30, 60 e 80 dias após a antese (DAA), e, no Laboratório de Tecnologia e Análise de Sementes, as sementes foram extraídas manualmente, com auxílio de uma lâmina, sendo avaliados os seguintes parâmetros: coloração dos frutos, paina e sementes; teor de água das sementes; massa de mil sementes; número de sementes por quilograma e a massa fresca e seca das sementes. A coloração dos frutos, paina e sementes foi definida por avaliação visual; o teor de água das sementes foi obtido utilizando-se duas subamostras de 15 sementes, pelo método de estufa a $105 \pm 3{ }^{\circ} \mathrm{C}$ por 24 horas (BRASIL, 1992), e a massa de mil sementes foi determinada segundo as Regras para Análise de Sementes (BRASIL, 1992), com os resultados expressos em grama. $\mathrm{O}$ número de sementes por quilograma e a massa fresca foram obtidos por regra de três simples, a partir dos valores da massa de mil sementes, e a massa seca das sementes foi obtida conjuntamente com a determinação do teor de água. $\mathrm{O}$ teste de germinação foi conduzido com quatro repetições de 25 sementes semeadas nos substratos sobre papel (SP), entre areia (EA) e entre vermiculita (EV). Os substratos foram colocados em placas de Petri, umedecidos com água destilada até atingir $60 \%$ da capacidade de retenção de água, calculado de acordo com Brasil (1992), à exceção do substrato sobre papel, que foi umedecido com água destilada equivalente a 2,5 vezes o peso do papel seco. As placas foram mantidas em câmara tipo $\mathrm{BOD}$, regulada à temperatura de $30^{\circ} \mathrm{C}$, com fotoperíodo de 8 horas de luz e 16 horas de escuro. Realizou-se a contagem das sementes germinadas diariamente por 15 dias, sendo consideradas germinadas as sementes com protrusão da raiz primária com 2,0 $\mathrm{mm}$. Determinou-se a porcentagem de germinação e o índice de velocidade de germinação (MAGUIRE, 1962).

A análise de variância foi realizada para cada teste em delineamento inteiramente casualizado (DIC), num esquema fatorial $3 \times 3$ (três períodos de maturação $\times$ três substratos), com quatro repetições, e a comparação entre as médias dos tratamentos foi efetuada pelo teste de Tukey $(\alpha=0,05)$, com auxílio do software SAEG 7.1 (SAEG, 1997). Os dados expressos em porcentagem foram transformados em arc sen $(\mathrm{x} / 100)^{1 / 2}$, para fins de análise estatística, e os dados para interpretação foram apresentados com as médias dos dados originais. 


\section{RESULTADOS E DISCUSSÃO}

Os dados médios mensais de temperaturas máximas, mínimas, médias, precipitação pluvial e umidade relativa ocorridas no período de floração e colheita das sementes encontram-se na figura 1. Os dados evidenciam que os fatores climáticos não exerceram influência na maturação, pois permaneceram estáveis ao longo do período experimental, com exceção da precipitação, a qual sofreu acentuada elevação no mês de agosto. No entanto, nesse período, boa parte dos frutos já se encontrava na fase final do processo de maturação, apresentando-se normalmente desenvolvidos.

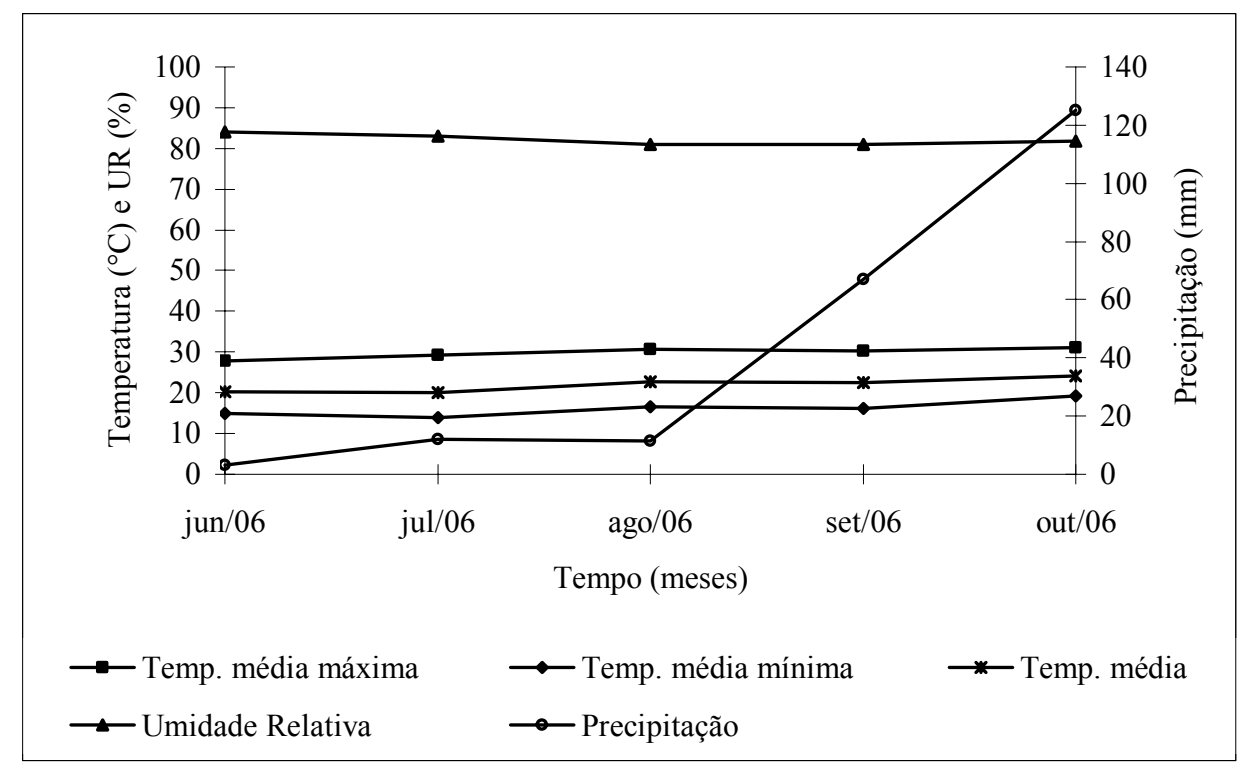

Figura 1. Dados médios mensais de temperaturas máximas, mínimas, médias, precipitação pluvial e umidade relativa do ar no período de florescimento e colheita das sementes de Pseudobombax grandiflorum.

Figure 1. Monthly averages data of maximum, minimum and average temperatures, pluvial precipitation and relative air humidity in the period of flowering and harvest of Pseudobombax grandiflorum seeds.

A partir da metade do mês de junho, aproximadamente $70 \%$ das plantas apresentavam flores. A antese (fase de abertura das flores) teve início no dia 10/06/2006. Os seguintes animais, possíveis polinizadores, foram observados visitando as flores de embiruçu: Centris sp. - Hymenoptera: Anthophoridae (mamangava); Apis mellifera - Hymenoptera: Apidae (abelha) e beija-flor (não identificado cientificamente). Foi possível observar a formação de frutos somente após cerca de 5 a 10 dias da antese, não havendo ainda a formação de sementes. Nessa fase, embora tenham sido etiquetadas flores em quantidades suficientes para coleta periódica, em vários pontos de desenvolvimento, houve perda de material e formação de poucos frutos, devido ao ataque por insetos e pela avifauna, principalmente por Trigona spinipes - Hymenoptera: Apidae (irapuá ou abelha-cachorro). A queda de flores, inflorescências e frutos causada por esse inseto é citada por Gallo et al. (2002) para diversas espécies vegetais. Estudando a maturação de sementes de Miconia cinnamomifolia (DC.) Naud na região serrana do Caparaó, em Ibitirama (ES), Lopes; Soares (2006) também relatam grandes dificuldades por perdas de material devido a intempéries e ao consumo pela avifauna. A antese ocorreu em junho/julho, estando os frutos maduros (deiscentes) em setembro/outubro, concordando com Lorenzi (2002), que afirma ser esta a época de floração e frutificação dessa espécie. Trinta dias após a antese, verificou-se a formação de frutos contendo as sementes imaturas. Nessa fase, o teor de água das sementes era alto (89,4\%). Com 60 DAA, houve acúmulo significativo de massa seca nas sementes, com redução no conteúdo de água $(60,7 \%)$, embora ele ainda continuasse elevado. Maior redução no teor de água foi verificada com 80 DAA, atingindo valores de $45 \%$ (Figura 2), corroborando Popinigis (1985) e Carvalho; Nakagawa (2000), segundo os quais no início da 
formação das sementes elas apresentam elevado grau de umidade, que ao longo da maturação decresce gradativamente. Verifica-se que, ao longo do período que sucedeu a antese, o teor de água e a massa seca das sementes apresentaram comportamento inversamente proporcional, com coeficiente de correlação linear altamente negativo $(-0,97)$. Comportamento similar foi verificado por Lopes et al. (2005) ao longo da maturação de sementes de quaresmeira (Tibouchina granulosa Cogn.).

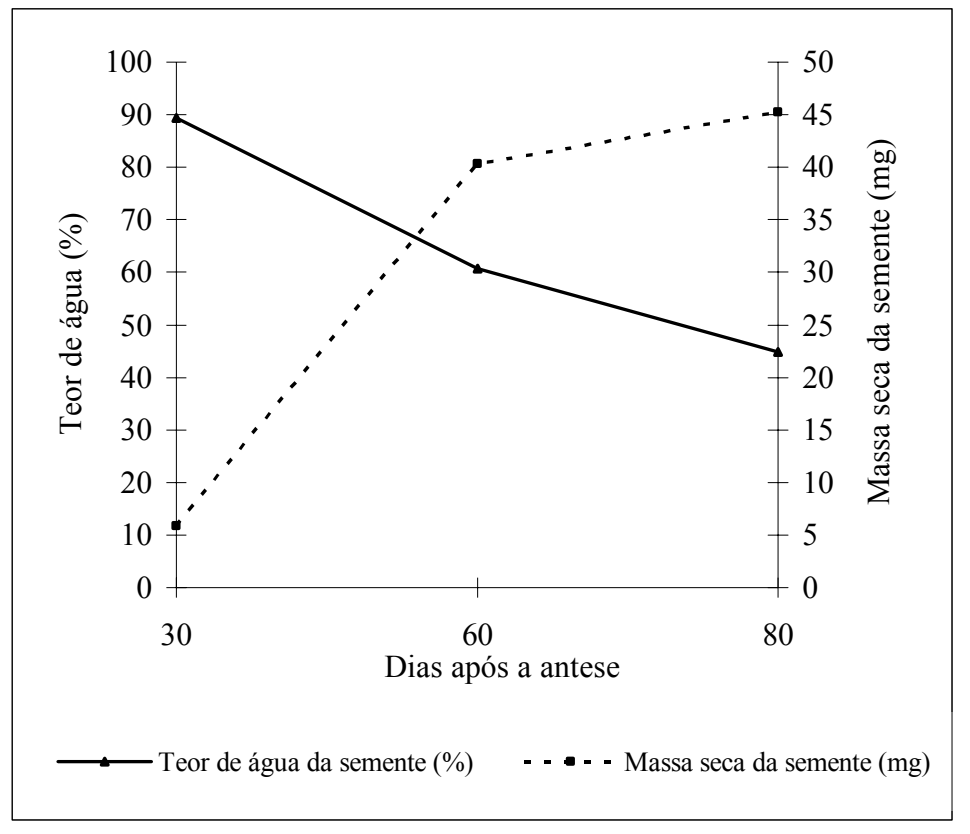

Figura 2. Variação do teor de água e da massa seca de sementes de Pseudobombax grandiflorum em diferentes estádios de maturação.

Figure 2. Variation of the water content and dry matter of Pseudobombax grandiflorum seeds in different phases of maturity.

$\mathrm{Na}$ tabela 1, são apresentadas as características físicas avaliadas nos frutos e nas sementes (número médio de sementes por quilograma; massas fresca, seca e de mil sementes; coloração do fruto, da paina e das sementes e o teor de água das sementes). Destaca-se que, quando os frutos estão maduros, a tonalidade da paina é dourada. Entretanto, Duarte (2006) afirma que entre as bombacáceas, apenas Spirotheca passifloroides Cuatrec. possui paina com essa coloração. A massa de mil sementes comportou-se proporcionalmente ao aumento da massa seca, e inversamente proporcional ao teor de água das sementes, apresentando coeficientes de correlação linear de 0,87 e - 0,73 , respectivamente.

Tabela 1. Atributos físicos dos frutos e sementes de Pseudobombax grandiflorum em diferentes estádios de maturação.

Table 1. Physical attributes of fruits and seeds of Pseudobombax grandiflorum at different phases of maturity.

\begin{tabular}{|c|c|c|c|c|c|c|c|c|}
\hline \multirow[b]{2}{*}{ DAA } & \multicolumn{3}{|c|}{ Coloração } & \multirow[b]{2}{*}{$\begin{array}{l}\text { Número de } \\
\text { sementes/kg }\end{array}$} & \multicolumn{4}{|c|}{ Semente } \\
\hline & Frutos & Paina & Sementes & & $\begin{array}{c}\text { Massa } \\
\text { de } 1000 \\
(g)\end{array}$ & $\begin{array}{c}\text { Massa } \\
\text { fresca } \\
(\mathrm{mg})\end{array}$ & $\begin{array}{c}\text { Massa } \\
\text { seca } \\
\text { (mg) }\end{array}$ & $\begin{array}{c}\text { Teor de } \\
\text { água } \\
(\%)\end{array}$ \\
\hline 30 & $\begin{array}{l}\text { Verde- } \\
\text { escuro }\end{array}$ & Branca & Branca & 20.068 & 49,83 & 49,8 & 5,87 & 89,4 \\
\hline 60 & Verde & Branca & Parda & 9.580 & 104,39 & 104,4 & 40,32 & 60,7 \\
\hline 80 & Verde & Dourada & $\begin{array}{l}\text { Acinzentada } \\
\text { com máculas } \\
\text { castanhas }\end{array}$ & 11.983 & 83,45 & 83,4 & 45,28 & 44,9 \\
\hline
\end{tabular}


Conforme verificado através da análise de variância, houve interação significativa entre os estádios de maturação e os substratos testados (Tabela 2).

Tabela 2. Germinação (\%) e índice de velocidade de germinação (IVG) de sementes de Pseudobombax grandiflorum em diferentes estádios de maturação e substratos.

Table 2. Germination (\%) and velocity of germination index (IVG) of Pseudobombax grandiflorum seeds in different phases of maturity and substrates.

\begin{tabular}{|c|c|c|c|c|c|c|}
\hline \multirow{3}{*}{ Substratos } & \multicolumn{3}{|c|}{ Germinação } & \multicolumn{3}{|c|}{ IVG } \\
\hline & \multicolumn{3}{|c|}{ Estádios de maturação } & \multicolumn{3}{|c|}{ Estádios de maturação } \\
\hline & 30 dias & 60 dias & 80 dias & 30 dias & 60 dias & 80 dias \\
\hline Papel & $0 \mathrm{Ac}$ & $13 \mathrm{Bb}$ & $90 \mathrm{Aa}$ & $0 \mathrm{Ac}$ & $0,575 \mathrm{Bb}$ & $1,738 \mathrm{ABa}$ \\
\hline Areia & $0 \mathrm{Ac}$ & $11 \mathrm{Bb}$ & $95 \mathrm{Aa}$ & $0 \mathrm{Ac}$ & $0,448 \mathrm{Bb}$ & $1,875 \mathrm{Aa}$ \\
\hline Vermiculita & $0 \mathrm{Ac}$ & $55 \mathrm{Ab}$ & $85 \mathrm{Aa}$ & $0 \mathrm{Ab}$ & $1,721 \mathrm{Aa}$ & $1,417 \mathrm{Ba}$ \\
\hline $\mathrm{CV}(\%)$ & & 17,31 & & & 26,5 & \\
\hline
\end{tabular}

Médias seguidas pela mesma letra maiúscula nas colunas e minúscula nas linhas não diferem entre si pelo de teste de Tukey, ao nível de $5 \%$ de significância.

Observa-se que sementes dos frutos colhidos com 30 DAA não apresentaram germinação em nenhum dos substratos testados, provavelmente pelo fato de a embriogênese ainda estar no princípio e as reações metabólicas que culminam com o prolongamento do eixo embrionário não serem realizadas. Além disso, nesse período, as sementes apresentavam alto teor de água (89,4\%) (Figura 2) e baixo conteúdo de massa seca $(5,87 \mathrm{mg}$ ) na sua composição (Tabela 1). De acordo com Popinigis (1985), nessa fase as sementes apresentam baixa germinação. Lopes; Soares (2006), trabalhando com Miconia cinnamomifolia, também não conseguiram obter germinação na fase inicial até 50 DAA.

Verificou-se que somente houve germinação em sementes de frutos colhidos com 60 DAA. Nesse período, o teor de água já havia se reduzido a $60,7 \%$, e o conteúdo de massa seca se elevado para 40,32 mg (Tabela 1). Quando a semente atinge o máximo conteúdo de massa seca e acentuada redução no teor de água, ela encontra-se no ponto de maturidade fisiológica (DELOUCHE, 1975; POPINIGIS, 1985; CARVALHO; NAKAGAWA, 2000). Nesse estádio de desenvolvimento, Howell et al. (1959) verificaram que o teor de água situa-se entre 50 e $60 \%$, tornando-se impróprio para a colheita, pois, embora teoricamente o ponto ideal para realizar a colheita seja o momento em que a semente atinge a maturação fisiológica, nesse ponto a semente ainda apresenta alto conteúdo de água.

Aos 60 dias, a germinação ainda é baixa (13 e 11\% para papel e areia, respectivamente). Entretanto, contrariando esse fator, com vermiculita é acusada uma germinação de 55\% (Tabela 2). O processo ocorre mais lentamente aos 60 DAA do que aos 80 DAA, quando acontece a deiscência natural dos frutos, exceto em vermiculita, em que se manteve o IVG verificado na coleta com 60 dias (IVG $=$ $1,721)$ também aos 80 dias $(\mathrm{IVG}=1,417)$.

De um modo geral, os substratos testados neste trabalho influenciaram sensivelmente a germinação das sementes de embiruçu, com maiores velocidades e percentuais em vermiculita quando as sementes ainda estavam com 60 DAA. A disponibilidade de água para a reidratação da semente é fundamental para o início de sua germinação, sendo a quantidade adicionada desta dependente, entre outros fatores, da dimensão do substrato. A vermiculita e a areia são substratos com excelentes qualidades para a germinação de sementes florestais (FIGLIOLIA et al., 1993). É provável que a capacidade de retenção de água de cada substrato, aliada às características intrínsecas que regulam o fluxo de água para as sementes, possa ter influenciado os resultados, corroborando Varela et al. (2005) e Alvino; Rayol (2007), uma vez que a vermiculita apresenta boa capacidade de absorção e retenção de água, enquanto que a areia possui dificuldade de manutenção de umidade, visto que apresenta desuniformidade de retenção e distribuição de água, drenando-a excessivamente, ficando a parte superior ressecada (FIGLIOLIA et al., 1993; ALVINO; RAYOL, 2007). Entretanto, Zamith; Scarano (2004) obtiveram porcentagem máxima de germinação de 95\% para sementes de embiruçu em canteiros contendo areia de restinga como substrato, o que concorda com o obtido neste trabalho, em areia no estádio de 80 DAA, com a qual, embora não tenha ocorrido diferença significativa para a germinação, o IVG foi superior aos dos demais substratos. Scalon et al. (2003), no entanto, não obtiveram boa germinação com substrato areia para sementes de Caesalpinia pelthophoroides Benth. 
Conforme Figliolia et al. (1993), recomenda-se vermiculita para sementes grandes e para as que possuem forma esférica, caso do embiruçu, pois o contato entre as sementes e o substrato é bem maior.

Em sementes de Acosmium nitens (Vog.) Yakovlev (VARELA et al., 2005) e Genipa americana L. (ANDRADE et al., 2000), o substrato vermiculita proporcionou os maiores valores de germinação e velocidade de germinação. Alvino; Rayol (2007) obtiveram em sementes de outra espécie da família Bombacaceae, Ochroma pyramidale (Cav. ex Lam.) Urb., a maior e mais rápida germinação com vermiculita, até mesmo recomendando esse substrato.

Devido à sujeira provocada pela paina quando os frutos estão maduros, o beneficiamento das sementes aos 60 dias para serem semeadas em vermiculita poderia ser recomendado. Entretanto, tendo em vista a dificuldade na abertura dos frutos nesse estádio, quando eles ainda são muito duros, o mais indicado é aguardar a deiscência dos frutos e lidar de forma cuidadosa com a paina, que é facilmente dispersada para o ambiente.

Aos 80 DAA, quando os frutos se encontravam completamente maduros, isto é, deiscentes, as sementes apresentaram as maiores porcentagens de germinação. Embora o percentual de sementes germinadas não tenha diferido entre os substratos utilizados, a velocidade do processo de germinação sofreu influência do substrato, sendo que, em areia, ocorreu mais rapidamente $(\mathrm{IVG}=1,875)$. Nessa fase, a paina é dourada e as sementes são acinzentadas, possuindo suaves máculas castanhas e apresentando ainda teor de água em torno de $45 \%$. Essas características físicas podem servir como índices práticos de maturação para a colheita antes da liberação das sementes.

Caso a semeadura seja realizada aos 60 DAA, a vermiculita é o substrato adequado, por apresentar maior percentual e velocidade de germinação. Por outro lado, no caso de se efetuar a semeadura após a deiscência dos frutos maduros (80 DAA), papel e areia também podem ser recomendados. Entretanto, em viveiros, o mais indicado é a areia, por ser de mais fácil obtenção, baixo custo e possibilitar maior praticidade. Além disso, Figliolia et al. (1993) comentam que a vermiculita possui alto custo.

\section{CONCLUSÕES}

Sementes de embiruçu com 60 dias após a antese apresentam maior porcentagem e velocidade de germinação em vermiculita.

Sementes colhidas de frutos deiscentes (80 dias) germinam bem em papel, areia e vermiculita, porém a velocidade de germinação nesse estádio é maior no substrato areia.

\section{AGRADECIMENTOS}

Os autores agradecem à CAPES, pela concessão de bolsa ao segundo e terceiro autores, ao CNPq, pela concessão de bolsa ao quarto autor, e à engenheira agrônoma Marilda Torres Capucho, pelo auxílio neste trabalho.

\section{REFERÊNCIAS}

ALVINO, F. O.; RAYOL, B. P. Efeito de diferentes substratos na germinação de Ochroma pyramidale (Cav. ex Lam.) Urb. (Bombacaceae). Ciência Florestal, Santa Maria, v. 17, n. 1, p. 71-75, 2007.

ANDRADE, A. C. S.; SOUZA, A. F.; RAMOS, F. N.; PEREIRA, T. S.; CRUZ, A. P. M. Germinação de sementes de jenipapo: temperatura, substrato e morfologia do desenvolvimento pós-seminal. Pesquisa Agropecuária Brasileira, Brasília, DF, v. 35, n. 3, p. 609-615, 2000.

BORGES, E. E. L.; BORGES, C. G. Germinação de sementes de Copaifera langsdorffii Desf. provenientes de frutos com diferentes graus de maturação. Revista Brasileira de Sementes, Brasília, DF, v. 1, n. 3, p. 45-47, 1979.

BRASIL. Ministério da Agricultura e Reforma Agrária. Regras para análise de sementes. Brasília, DF, 1992. $365 \mathrm{p}$.

CARVALHO, N. M.; NAKAGAWA, J. Sementes: ciência, tecnologia e produção. 4. ed. Jaboticabal: FUNEP, 2000. 588 p. 
CASTEllani, E. D.; AGUIAR, I. B. Condições preliminares para a germinação de sementes de candiúba (Trema micrantha (L.) Blume.). Revista Brasileira de Engenharia Agrícola e Ambiental, Campina Grande, v. 2, n. 1, p. 80-83, 1998.

DELOUCHE, J. C. Recentes conquistas de pesquisa tecnológica de sementes. In: DELOUCHE, J.C. Pesquisas em sementes no Brasil. Brasília, DF: AGIPLAN, 1975. p. 27-36.

DUARTE, M. C. Diversidade de Bombacaceae Kunth no Estado de São Paulo. 99 p. Dissertação (Mestrado em Biodiversidade Vegetal e Meio Ambiente) - Instituto de Botânica da Secretaria de Estado do Meio Ambiente, São Paulo, 2006.

FIGLIOLIA, M. B.; OlivEIRA, E. C.; PIÑA-RODRIGUES, F. C. M. Análise de sementes. In: AGUIAR, I. B.; PIÑA-RODRIGUES, F. C. M.; FIGLIOLIA, M. B. (Coords.) Sementes florestais tropicais. Brasília, DF: ABRATES, 1993. p.137-174.

FONSECA, F. L.; MENEGARIO, C.; MORI, E. S.; NAKAGAWA, J. Maturidade fisiológica das sementes do ipê-amarelo, Tabebuia chrysotricha (Mart. Ex DC.) Standl. Scientia Forestalis, Piracicaba, n .69, p. 136-141, 2005.

GALlO, D.; NAKANO, O.; SILVEIRA NETO, S.; CARVALHO, R. P. L.; BATISTA, G. C.; BERTI FILHO, E.; PARRA, J. R. P.; ZUCCHI, R. A.; ALVES, S. B.; VENDRAMIM, J. D.; MARCHINI, L. C.; LOPES, J. R. S.; OMOTO, C. Entomologia agrícola. 3. ed. Piracicaba: FEALQ, 2002. 920 p.

HOWELL, R. W.; COLLINS, F. I.; SEDGEWICK, V. E. Respiration of soybean related to weathering loses during ripening. Agronomy Journal, Madison, v. 51, n. 11, p. 677-679, 1959.

LOPES, J. C.; DIAS, P. C.; PEREIRA, M. D. Maturação fisiológica de sementes de quaresmeira. Pesquisa Agropecuária Brasileira, Brasília, DF, v. 40, n. 8, p. 811-816, 2005.

LOPES, J. C.; SOARES, A. S. Estudo da maturação de sementes de carvalho vermelho (Miconia cinnamomifolia (DC) Nauad). Ciência e Agrotecnologia, Lavras, v. 30, n. 4, p. 623-628, 2006.

LORENZI, H. Árvores brasileiras: manual de identificação e cultivo de plantas arbóreas nativas do Brasil. Nova Odessa: Plantarum, 2002. v. 1.

MAGUIRE, J. D. Speed of germination aid in selection and evaluation for seedling emergence and vigor. Crop Science, Madison, v. 2, n. 2, p. 176-177, 1962.

NiCOlOSO, F. T.; FORTUNATO, R. P.; ZANCHETTI, F.; CASSOL, L. F.; EISINGER, S. M. Recipientes e substratos na produção de mudas de Maytenus ilicifolia e Apuleia leiocarpa. Ciência Rural, Santa Maria, v. 30, n. 6, p. 987-992, 2000.

PIÑA-RODRIGUES, F. C. M.; AGUIAR, I. B. Maturação e dispersão de sementes. In: AGUIAR, I. B.; PIÑA-RODRIGUES, F. C. M.; FIGLIOLIA, M. B. (Coords.) Sementes florestais tropicais. Brasília, DF: ABRATES, 1993. p. 215-274.

POPINIGIS, F. Fisiologia da semente. Brasília, DF: AGIPLAN, 1985. 289 p.

SAEG - Sistema para Análises Estatísticas e Genéticas: SAEG versão 7.1. Viçosa: UFV/FUNARBE, 1997.

SCALON, S. P. Q.; MUSSURY, R. M.; ALMEIDA, K. A.; RIGONI, M. R. Efeito do álcool e substrato na germinação de sementes de sibipiruna (Caesalpinia pelthophoroides Benth.) colhidas no chão e retiradas da vagem. Ciência e Agrotecnologia, Lavras, v. 27, n. 2, p. 389-392, 2003.

VARELA, V. P.; COSTA, S. S.; RAMOS, M. B. P. Influência da temperatura e do substrato na germinação de sementes de itaubarana (Acosmium nitens (Vog.) Yakovlev) - Leguminosae, Caesalpinoideae. Acta Amazônica, Manaus, v. 35, n. 1, p. 35-39, 2005.

ZAMITH, L. R.; SCARANO, F. R. Produção de mudas de espécies das Restingas do município do Rio de Janeiro, RJ, Brasil. Acta Botânica Brasílica, São Paulo, v. 18, n. 1, p. 161-176, 2004. 